\title{
Barriers to Dietary Salt Reduction among Hypertensive Patients
}

\author{
Saruna Ghimire, ${ }^{1}$ Naveen Shrestha, ${ }^{1,2}$ Karen Callahan ${ }^{3}$
}

${ }^{1}$ Agrata Health and Education-Nepal, Kathmandu, Nepal, ${ }^{2}$ School of Health and Allied Science, Pokhara University, Pokhara, Nepal, ${ }^{3}$ School of Community Health Science, University of Nevada, Las Vegas.

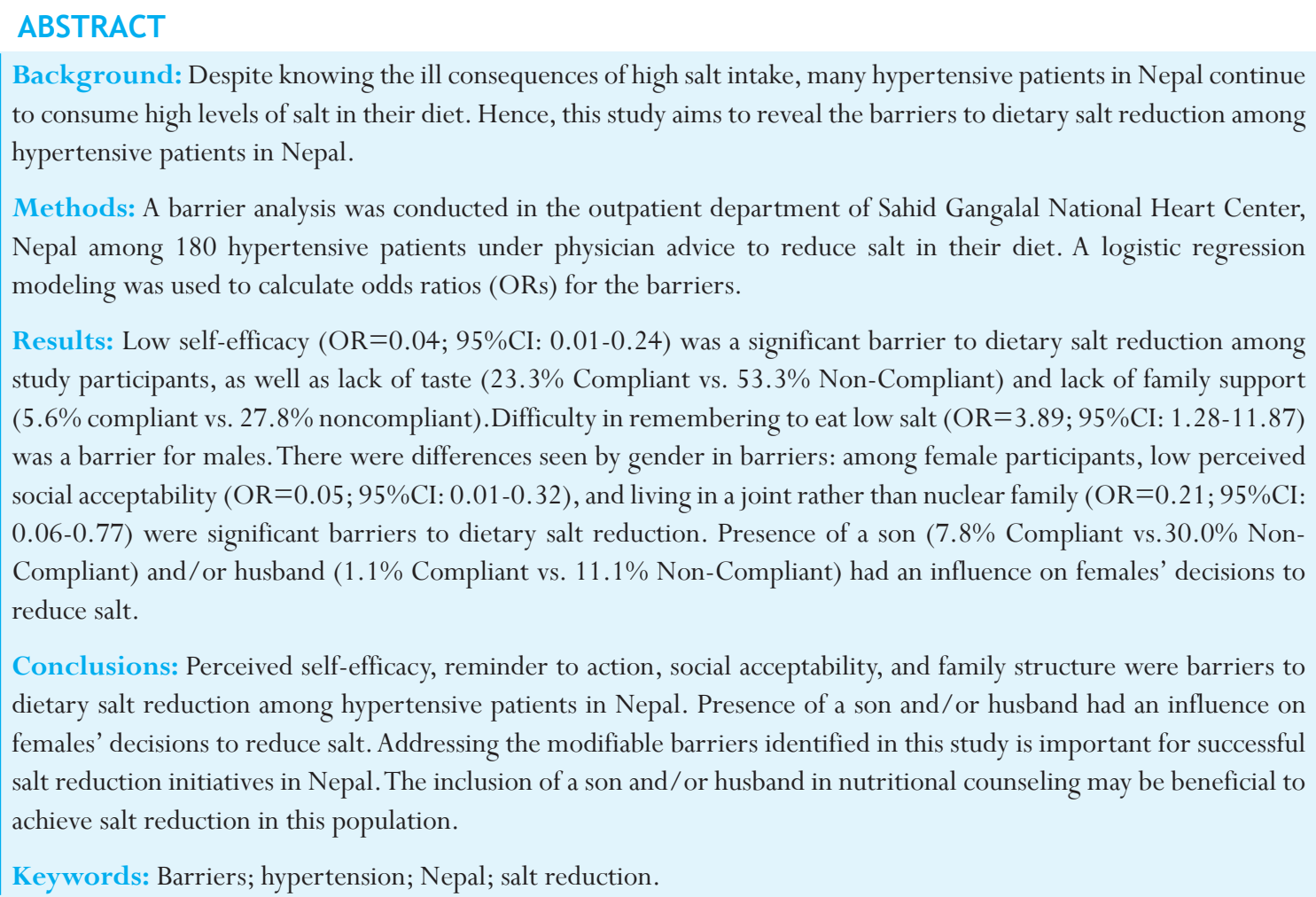

\section{INTRODUCTION}

Hypertension is a burgeoning major public health issue in Nepal. ${ }^{1,2}$ High salt intake is an important behavioural and biological risk factor for hypertension. ${ }^{3} \mathrm{~A}$ modest reduction in salt intake of $6 \mathrm{~g} /$ day lowered blood pressure by $7 / 4 \mathrm{~mm}$ of $\mathrm{Hg}$ diastolic in hypertensive patients. ${ }^{4}$ Interestingly, the average per-person salt intake among Nepalese is relatively high; ${ }^{5}$ estimated to be 10-13 grams /day, ${ }^{6}$ which far exceeds the World Health Organization's recommended daily level of $5 \mathrm{~g}$ or less dietary salt intake. ${ }^{7}$ A recent survey in Nepal found that three-quarters of the hypertensive cases received advice to reduce salt intake, $78.5 \%$ of respondents were aware of the health problems associated with high salt intake, and $10.9 \%$ were aware that their salt intake was high. ${ }^{5}$ Thus, despite knowledge about the ill consequences, many people continue to consume high levels of salt in their diet. There is no salt reduction strategy adopted by the Government of Nepal. Hence, self-management of a low-sodium diet among Nepalese individuals is of utmost importance. To motivate people to reduce salt in their diet, a solid understanding of barriers encountered by those under salt reduction recommendation is necessary. Health professionals can better facilitate behavior change by identifying such barriers to compliance. ${ }^{8}$ Few international studies ${ }^{9-11}$ have addressed these issues. Hence, this study aims to identify the barriers to dietary salt reduction among hypertensive patients.

\section{METHODS}

We conducted a barrier analysis following methodologies defined by Kittle et al. ${ }^{12}$ This design is similar to a crosssectional case-control design, ${ }^{13}$ but cases and controls
DOI: http://dx.doi.org/10.3126/ jnhrc.v16i2.20296
Correspondence: Ms Saruna Ghimire, Agrata Health and Education-Nepal Kathmandu, Nepal. Email: sarunaghimire@gmail.com, Phone:+9779841660628. 
are defined by presence or absence of a health behavior rather than disease status. Hence, we replaced the words "case" with "Compliant" and "control" with "non-Compliant," denoting persons with and without a health behavior, respectively. The study was conducted among hypertensive patients attending the outpatient department (OPD) of Sahid Gangalal National Heart Center, Kathmandu, Nepal from June-July, 2015. Ethical approval for the study was granted by the Ethical Review Board at the Nepal Health Research Council. Permission was also obtained from Sahid Gangalal National Heart Center, Kathmandu. Informed written consent was taken from each respondent. Participation was voluntarily.

Eligible participants were adult hypertensive patients (confirmed by patient's OPD card) who had received recommendations from their consultants to lower their dietary salt intake at least 12 weeks before commencement of the study. Hypertensive patients who followed the physician's recommendations and reduced their dietary salt intake, as ascertained by self-reporting on behavior screening questions developed, ${ }^{12}$ were in the Compliant category $(n=90)$, while those who did not follow the recommendations were in the non-Compliant category $(n=90)$. Patients with other cardiac and renal comorbidities that could influence adherence to low salt diet were excluded.

The sample size for the study was 180 people, calculated based on a p-value of 0.05 , a relative risk of 3.0, an alpha error of $5 \%$, to provide a power of $80 \% .{ }^{12}$ At Sahid Gangalal National Heart Center, almost all patients attend OPD without a prior appointment. Therefore, due to the absence of sampling frame, all eligible participants on the day of data collection were recruited until the desired sample size was achieved, in each group. Individual interviews were conducted during patients waiting times. The study tool was pre-tested among 18 patients meeting the study inclusion criteria at a different heart clinic in Maharajgunj, Kathmandu. Pretest responses were not included in the final analysis.

Based on the tenets of the Health belief model (HBM) ${ }^{14}$ and the theory of planned behaviour (TPB), ${ }^{15}$ seven key determinants of human behavior, i.e., perceived selfefficacy, perceived social acceptability, perceived action efficacy, cues for action, accessibility of materials, perceived susceptibility and perceived severity, were examined; all dichotomized (yes/no) response.Selfefficacy refers to the belief in one's own capacity to do a given behavior. ${ }^{16}$ Self-efficacy is important for behavior change because if a person believes that he cannot change the behavior, then he will not even attempt to change it. ${ }^{16}$ In our study, self-efficacy indicated the respondent's confidence in being able to maintain a low salt diet. In an open-ended question, we also asked about the important factors that made salt reduction easier or difficult. Subjective norm, or perceived social acceptability, evaluates the respondents' perceptions of their significant others' attitudes toward the targeted behavioral change. ${ }^{15}$ Hence, we asked respondents if most people around them approved/disapproved of their behavior of low salt intake. In an open-ended question, we also asked about the important people approving or disapproving the behavior. Perceived action efficacy, is the perception that the behavior is useful in decreasing the risk of disease or its consequences; people will more likely adopt a behavior when they think that the behavior is beneficial. ${ }^{14,17}$ In our study, we asked participants if dietary salt reduction is effective to control their hypertension. Cues for action determines whether a person can remember to do the recommended advice. If someone cannot remember the recommendations and what was advised to do, then other determinants do not matter. To assess this, we asked the participants how difficult is it to remember to follow the doctor's advice concerning low salt indiet. Two items measured accessibility: availability of materials needed to eat/ cook less salty food at home and availability of options to eat less salty food outside the home. According to HBM, perceived susceptibility and perceived severity are the driving factors for behavior change. ${ }^{17}$ Perceived susceptibility, or risk, indicates the respondent's perception of his/her likelihood of experiencing hypertension-related complications. Greater perceived risk of disease or its consequences is associated with greater likelihood of adopting the behavior. ${ }^{14}$

Socio-demographic characteristics evaluated in our study included age, sex, ethnicity, educational status, occupation, marital status, family type, and consumption of anti-hypertensive medication. The categories for ethnicity were adopted from 'caste/ethnic groupings' of Nepal Health Management Information System; related categories were combined to obtain three ethnic groups: Upper Caste, Janjatis (included disadvantaged Janjatis, disadvantaged non-Dalit Terai caste groups, and relatively advantaged Janjatis) and Dalit and minorities (included Dalit and Religious Minorities). Education status was categorized into four groups as follows: illiterate; informal (no formal schooling, some literacy); formal education (any years of formal schooling) and a university education (education beyond high school). The categories for occupation were adopted from the Nepal Standard Occupation Classification -NSOC-99. Marital status was categorized as married, unmarried and widow/separated. Family type was recorded as 
a nuclear, joint and extended family. Clinical data, abstracted from respondents' OPD cards, included diagnosis of hypertension (dichotomized, yes/no), prescribed medicines (dichotomized, yes/no), and advice to reduce salt consumption (dichotomized, yes/ no).

Epi-Data version 3.1 was used for data management. Chisquare tests and independent t-tests, where applicable, were performed to compare the socio-demographic characteristics between those who were Compliant and those who were non-Compliant. A logistic regression model was used to calculate crude and adjusted odds ratios (ORs) and their corresponding 95\% confidence intervals for the barriers between the Compliant and non-Compliant groups. Because some of the independent variables showed rare event phenomenon, we used Firth approach to logistic regression. ${ }^{18}$ The multivariate models were adjusted for the predictors that were significant in univariate analyses. Frequencies of openended responses are reported. Data analyses were performed in Stata 13.0 (Stata Corporation, College Station, TX, USA). Two-tailed P-values less than 0.05 were considered statistically significant.

\section{RESULTS}

A total of 180 respondents, equal proportions of males and females, were included in this study. The sociodemographic characteristics of the study participants are presented in Table 1. According to analyses of group differences, the participants in the Compliant and non-Compliant groups were similar in most sociodemographic aspects ( $p>0.05)$ including ethnicity, education, occupation, and marital status. However, Compliant and non-Compliant participants varied by type of family. Most of the Compliant participants lived in a nuclear family situation whereas most of the nonCompliants lived in joint families (Table 1).

\section{Table 1. Comparison of respondent characteristics.}

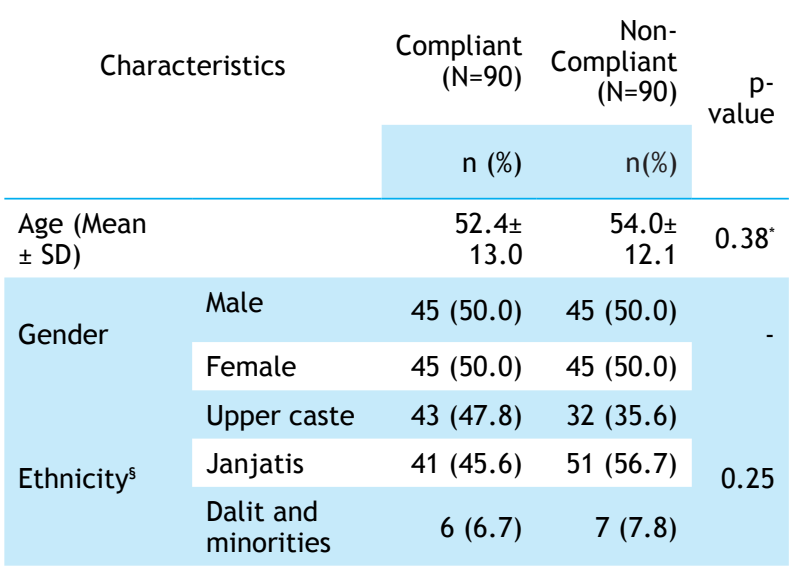

\begin{tabular}{|c|c|c|c|c|}
\hline \multirow{4}{*}{$\begin{array}{l}\text { Education } \\
\text { Level }\end{array}$} & Illiterate & $9(10.0)$ & $13(14.4)$ & \multirow{4}{*}{0.06} \\
\hline & Informal & $20(22.2)$ & 19 (21.1) & \\
\hline & Formal & $56(62.2)$ & $43(47.8)$ & \\
\hline & $\begin{array}{l}\text { University } \\
\text { Education }\end{array}$ & $5(5.6)$ & $15(16.7)$ & \\
\hline \multirow{4}{*}{ Occupation } & $\begin{array}{l}\text { Elementary } \\
\text { occupations }\end{array}$ & $48(53.3)$ & $45(50.0)$ & \multirow{4}{*}{0.64} \\
\hline & $\begin{array}{l}\text { Clerical, } \\
\text { service } \\
\text { and sales } \\
\text { workers }\end{array}$ & $13(14.4)$ & $19(21.1)$ & \\
\hline & Professionals & $18(20.0)$ & $18(20.0)$ & \\
\hline & $\begin{array}{l}\text { Agricultural } \\
\text { workers }\end{array}$ & $11(12.2)$ & $8(8.9)$ & \\
\hline \multirow{2}{*}{$\begin{array}{l}\text { Marital } \\
\text { status }\end{array}$} & Married & $82(91.1)$ & $83(92.2)$ & \multirow{2}{*}{0.79} \\
\hline & Widowed & $8(8.9)$ & $7(7.8)$ & \\
\hline \multirow{2}{*}{$\begin{array}{l}\text { Type of } \\
\text { family }\end{array}$} & Nuclear & $58(64.4)$ & $42(46.7)$ & \multirow[b]{2}{*}{0.02} \\
\hline & $\begin{array}{l}\text { Joint/ } \\
\text { Extended }\end{array}$ & $32(35.6)$ & $48(53.3)$ & \\
\hline \multirow{2}{*}{$\begin{array}{l}\text { Consumed } \\
\text { anti- } \\
\text { hypertensive } \\
\text { medicines }\end{array}$} & Yes & $77(85.6)$ & $78(86.7)$ & \multirow[b]{2}{*}{0.83} \\
\hline & No & $13(14.4)$ & $12(13.3)$ & \\
\hline
\end{tabular}

"Denotes independent t-test and otherp-value comes from Chi-square test.

${ }^{5}$ Nepal Health Management Information System's caste/ ethnic groupings were used. The Janjatis group in the table includes disadvantaged Janjatis, disadvantaged non-Dalit Terai caste groups, and relatively advantaged Janjatis.

In the univariate analysis, behavioral determinants including perceived self-efficacy, perceived social acceptability, reminder to action, perceived action efficacy, and family type were significant determinants of salt reducing behavior (Table 2 ). In the multivariate analysis, adjusted for age, gender and all significant factors from the univariate analyses, perceived selfefficacy, perceived social acceptability, reminder to action, and family type remained statistically significant predictors of salt-reduction compliance.

Participants who were non-Compliant were more likely to have lower self-efficacy, with $96 \%$ lower odds of believing that they were capable of reducing salt intake $(\mathrm{OR}=0.04 ; 95 \% \mathrm{Cl}: 0.01-0.24)$. The findings were similar for both male and females. Similarly, non-Compliant participants were less likely to believe that their significant others would support their salt reduction (OR $=0.09 ; 95 \% \mathrm{Cl}: 0.02-0.34)$. In gender stratified analysis, social acceptability was a significant barrier only for females. Participants who were non-Compliant had higher odds of forgetting to eat low salt food compared to those who were Compliant $(\mathrm{OR}=3.44 ; 95 \% \mathrm{Cl}: 1.42$ - 8.32); however, these findings were significant only for males in stratified analysis. The odds of being non- 
Compliant were $43 \%$ lower among participants living in a nuclear family $(\mathrm{OR}=0.43 ; 95 \% \mathrm{Cl}: 0.19-0.94)$ than those living in a joint family (Table 2). However, in stratified analysis, family type was a barrier to compliance only for female participants (Table 2).

\section{Table 2. Barriers to dietary salt reduction among the respondents.}

\begin{tabular}{|c|c|c|c|c|c|c|}
\hline \multirow{3}{*}{ Determinants } & \multicolumn{6}{|c|}{ Non-Compliant Odds Ratio $(95 \% \mathrm{CI})$ (Reference = Compliant) } \\
\hline & \multicolumn{3}{|c|}{ Univariate analysis } & \multicolumn{3}{|c|}{ Multivariate analysis } \\
\hline & Both & Male & Female & Both & Male & Female \\
\hline $\begin{array}{l}\text { Self-efficacy (Believes that } \\
\text { they can reduce salt intake) }\end{array}$ & $\begin{array}{r}0.02(0.01- \\
0.13)\end{array}$ & $\begin{array}{r}0.05(0.01- \\
0.26)\end{array}$ & $\begin{array}{r}0.02(0.001- \\
0.28)\end{array}$ & $\begin{array}{r}0.04(0.01- \\
0.24)^{a}\end{array}$ & $\begin{array}{r}0.09(0.01- \\
0.56)^{b}\end{array}$ & $\begin{array}{r}0.03(0.01- \\
0.53)^{\mathrm{b}}\end{array}$ \\
\hline $\begin{array}{l}\text { Social acceptability (Believes } \\
\text { they have family, community } \\
\text { support for reducing salt) }\end{array}$ & $\begin{array}{r}0.06(0.02- \\
0.18)\end{array}$ & $\begin{array}{r}0.10(0.03- \\
0.42)\end{array}$ & $\begin{array}{r}0.04(0.01- \\
0.20)\end{array}$ & $\begin{array}{r}0.09(0.02- \\
0.34)^{\mathrm{a}}\end{array}$ & $\begin{array}{r}0.34(0.06- \\
1.86)^{b}\end{array}$ & $\begin{array}{r}0.05(0.01- \\
0.32)^{\mathrm{b}}\end{array}$ \\
\hline $\begin{array}{l}\text { Accessibility of materials } \\
\text { (Believes they have access to } \\
\text { low salt food materials) }\end{array}$ & $\begin{array}{r}0.48(0.18- \\
1.31)\end{array}$ & $\begin{array}{r}0.56(0.16- \\
1.94)\end{array}$ & $\begin{array}{r}0.42(0.09- \\
2.00)\end{array}$ & - & - & - \\
\hline $\begin{array}{l}\text { Accessibility of services } \\
\text { (Believes they have access } \\
\text { to low salt food when eating } \\
\text { outside the home) }\end{array}$ & $\begin{array}{r}0.52(0.14- \\
1.97)\end{array}$ & $\begin{array}{r}0.69(0.13- \\
3.73)\end{array}$ & $\begin{array}{r}0.41(0.06- \\
2.90)\end{array}$ & - & - & - \\
\hline $\begin{array}{l}\text { Reminder (Believes it is } \\
\text { difficult to remember to eat } \\
\text { low salt food) }\end{array}$ & $\begin{array}{r}5.50(2.67- \\
11.36)\end{array}$ & $\begin{array}{r}6.93(2.52- \\
19.05)\end{array}$ & $\begin{array}{r}4.09(1.48- \\
11.31)\end{array}$ & $\begin{array}{r}3.44(1.42- \\
8.32)^{\mathrm{a}}\end{array}$ & $\begin{array}{r}3.89(1.28- \\
1.87)^{b}\end{array}$ & $\begin{array}{r}2.37(0.57- \\
9.81)^{\mathrm{b}}\end{array}$ \\
\hline $\begin{array}{l}\text { Perceived risk (Believe } \\
\text { eating high salt food will } \\
\text { lead to serious hypertension } \\
\text { complications) }\end{array}$ & $\begin{array}{r}0.52(0.20- \\
1.33)\end{array}$ & $\begin{array}{r}1.0(0.31- \\
3.23)\end{array}$ & $\begin{array}{r}0.17(0.03- \\
1.05)\end{array}$ & - & - & - \\
\hline $\begin{array}{l}\text { Perceived severity (Believes } \\
\text { hypertension is a serious health } \\
\text { problem) }\end{array}$ & $\begin{array}{r}0.84(0.26- \\
2.71)\end{array}$ & $\begin{array}{r}0.61(0.15- \\
2.48)\end{array}$ & $\begin{array}{r}1.71(0.22- \\
13.47)\end{array}$ & - & - & - \\
\hline $\begin{array}{l}\text { Action efficacy (Believes eating } \\
\text { less salt in diet will control } \\
\text { hypertension) }\end{array}$ & $\begin{array}{r}0.50(0.25- \\
0.98)\end{array}$ & $\begin{array}{r}0.89(0.35- \\
2.27)\end{array}$ & $\begin{array}{r}0.27(0.10- \\
0.74)\end{array}$ & $\begin{array}{r}0.63(0.26- \\
1.52)^{\mathrm{a}}\end{array}$ & $\begin{array}{r}0.66(0.22- \\
1.99)^{b}\end{array}$ & $\begin{array}{r}0.67(0.14- \\
3.31)^{\mathrm{b}}\end{array}$ \\
\hline Family Type (Nuclear) & $\begin{array}{r}0.49(0.27- \\
0.88)\end{array}$ & $\begin{array}{r}1.00(0.44- \\
2.28)\end{array}$ & $\begin{array}{r}0.23(0.10- \\
0.55)\end{array}$ & $\begin{array}{r}0.43(0.19- \\
0.94)^{a}\end{array}$ & $\begin{array}{r}0.76(0.28- \\
2.08)^{b}\end{array}$ & $\begin{array}{r}0.21(0.06- \\
0.77)^{\mathrm{b}}\end{array}$ \\
\hline
\end{tabular}

${ }^{a}$ Adjusted for age, gender, self-efficacy, social acceptability, reminder, action efficacy and family type, ${ }^{\mathrm{b}}$ Adjusted for age, self-efficacy, social acceptability, reminder, action efficacy and family type
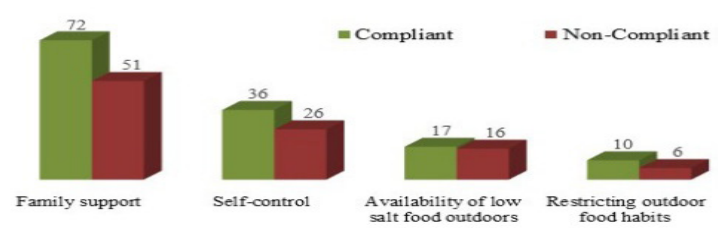

salt reduction easier

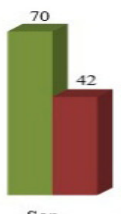

Son

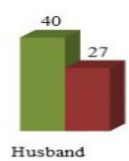

Husband

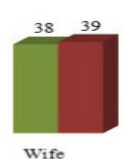

wife

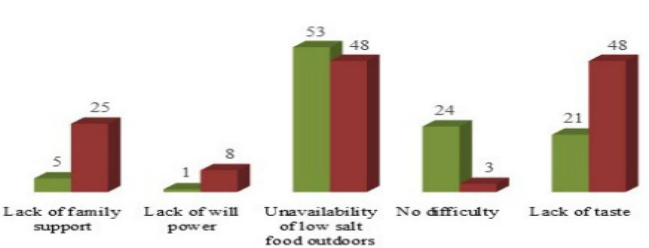

Fig 1B. What makes salt reduction difficult

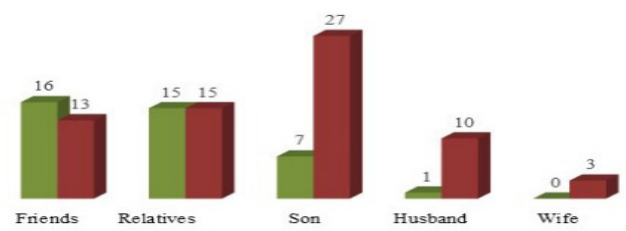

Fig 1D. People disapproving salt reduction 
Other aspects of barriers were explored through openended follow-up questions (Figure 1). Compared to non-Compliant participants, more Compliant individuals listed family support and self-control as factors that made compliance easier (Figure 1A). Lack of family support and lack of taste were listed by non-Compliant participants as barriers (Figure 1B). When asked about people who approved or disapproved the behavior, the role of a son was important (Figure 1C and 1D). Similarly, husband's approval or disapproval was important for female participants (Figure 1C and 1D).

\section{DISCUSSION}

Self-efficacy, social acceptability, reminder to action, and family type were significant determinants of dietary salt reduction among hypertensive patients in Nepal. The results of the current study are important because they provide initial evidence of perceived barriers among hypertensive patients in the context of Nepal.

In previous studies, self-efficacy was found to be the most salient predictor of health-promoting behaviors..$^{19,20}$ Having a deficit in a behavioral skill is as a major barrier to adopting healthy behaviors, ${ }^{21}$ which is consistent with our study, where self-efficacy was much higher among the Compliant group. Indeed, people are more likely to adopt a health behavior only if they think they will be successful. ${ }^{16}$ Counseling by health professionals and those who were successful to change their behavior can be helpful in motivating those who could not comply with the behavior.

Family support was identified as a major enabling factor for compliance whereas lack of taste and lack of family support were barriers that made compliance difficult. Family conflict, ${ }^{10}$ and lack of family acceptance ${ }^{11}$ have also been reported as key barriers to sodium-restricted diet in other studies. These findings show that health behavior is a social phenomenon and compliance is influenced by social embeddedness. As the practice of dietary salt reduction takes place in the family, and social settings, and thus likely to impact family and social dynamics, ${ }^{22}$ theories of health behavior change suggest a need for social support as a crucial component. ${ }^{15}$ Family support can promote compliance to behavior by encouraging optimism, self-esteem, and self-efficacy, buffering stress, and influencing change in negative health behaviors. ${ }^{22}$

In addition to this study, lack of taste has been reported as key barriers to sodium-restricted diet in many other studies. ${ }^{9,23}$ Since lack of taste, has been the most consistently identified barrier to adherence to a low salt diet, future strategies to increase compliance should aim to improve food taste without adding salt, such as adopting sodium-replacement/partial replacement salts. Sodium replacements salts have the same taste as standard table salt but use potassium instead of sodium as their key ingredient. ${ }^{24}$ They are also useful for lowering blood pressure because of the helpful effects of potassium. ${ }^{25}$ However, care should be taken before replacing table salt, especially in the Nepali context, where table salt is the key source of iodine for the population. It will be essential to monitor dietary iodine adequacy or provide iodine substitute before replacing table salt. ${ }^{26}$

This study found an influence of gender on barriers to compliance. Perceived social acceptability and family type were significant barriers to dietary salt reduction for women but not for men, which reflects the patriarchal Nepalese society. ${ }^{27}$ In Nepal, this difference is not surprising because a woman's life and decision making is strongly influenced by the male members like father, husband and son. ${ }^{28}$ This was evident in this study as husband and/or son had an influential role in participant's decision to low salt compliance. Also, living in a nuclear family was a predictor of compliance to low salt diet among female. The competing demands between patient and family members may act as a barrier to dietary compliance. ${ }^{29}$ In a joint family, the competing demands of many family member's needs to be met, which may limit patients' time and energy and introduce stress that can negatively affect patients who are trying to comply to low salt. ${ }^{29}$ Additionally, family structure is a key determinant of women's authority in decision making. A woman in a nuclear household is more likely than women in joint families to participate in family decisions, ${ }^{28}$ which may explain our finding that compliance was more likely in nuclear family types. Moreover, it was very important to have family support for salt-reduction behavior. Specifically, for women, having a son and/or husband who was supportive or not supportive was identified as a key barrier and/or enabler to compliance with dietary salt reduction. For policy implications, this suggests that until societal norms change significantly to empower women, the success of salt reduction among women could be enhanced by including important males in medical consultations and, specifically, counseling them on their role in creating a supportive family environment for salt reduction in the hypertensive patient.

Factors such as difficulty when eating out;23 and difficulty in understanding food labels/salt contents ${ }^{23}$ have been identified as prominent barriers to salt reduction in 
other studies. However, these were not barriers in this study. One reason for such inconsistency may be that there is significant variation in the levels and patterns of salt consumption between countries. ${ }^{30}$ For example, processed foods and restaurant services are the main sources of dietary salt in developed countries, while in Nepal, table salt used in cooking is the primary source of sodium.

This study is subject to some limitations, including the potential for misclassification of cases and controls as Compliant and non-Compliant due to self-reported data. Although, self-report is one of the most feasible measures to assess diet adherence level, nevertheless, there is a gap between self-reporting and the objective evidence. ${ }^{31}$ Adherence to recommended dietary salt reduction may be overestimated ${ }^{32}$ in order to please the researchers, especially given the high level of knowledge about the benefits of salt reduction among participants. Additionally, all the barriers reported are perceived and may not objectively reflect reality. Also, recruitment followed convenient sampling. Nevertheless, it provides preliminary findings to understand the barriers in Nepalese social context and have great potential to provide information for clinical practice in Nepalese context. Since Sahid Gangalal National Heart Center in Kathmandu is a national referral center for heart disease, drawing patients from most parts of the country, we can assume the participants are fairly representative of the diagnosed hypertensive patients in Nepal. However, the findings of this study may not be applicable to settings with different dietary pattern and lifestyle factors.

\section{CONCLUSIONS}

Perceived self-efficacy, perceived social acceptability, and reminders to action were important barriers to dietary salt compliance among hypertensive patients attending SGNHC. We found an influence of gender on barriers to compliance.

\section{ACKNOWLEDGEMENTS}

The authors would like to extend sincere gratitude to Mr. Praful Pradhananga, AHEAD-Nepal, for his continuous support since the inception of this study. A sincere appreciation goes to Sahid Gangalal National Heart Center, Kathmandu and the Heart Clinic, Maharajgunj, Kathmandu for allowing us to conduct and pre-test this study within their premises respectively.

\section{REFERENCES}

1. Vaidya A, Pokharel PK, Nagesh S, Karki P, Kumar S, Majhi S. War veterans of Nepal and their blood pressure status: a population-based comparative study. J Hum Hypertens. 2007 Nov;21(11):900-3.[PMID][DOI]

2. Vaidya A, Pathak RP, Pandey MR. Prevalence of hypertension in Nepalese community triples in 25 years: a repeat cross-sectional study in rural Kathmandu. Indian Heart J. 2012 Mar-Apr;64(2):128-31.[PMID][DOI]

3. World Health Organisation. A global brief on hypertension: Silent killer, global public health crisis, World Health Day 2013. Geneva.2013. [Full Text]

4. He FJ, MacGregor GA. Effect of modest salt reduction on blood pressure: a meta-analysis of randomized trials. Implications for public health. J Hum Hypertens. 2002 Nov;16(11):761-70[PMID][DOI]

5. Aryal K, Neupane S, Mehata S, Vaidya A, Singh S, Paulin F, et al. Non communicable diseases risk factors: STEPS Survey Nepal 2013. Kathmandu: Nepal Health Research Council2014.[Full Text]

6. Kawasaki T, Itoh K, Uezono K, Ogaki T, Yoshimizu Y, Kobayashi $\mathrm{S}$, et al. Investigation of high salt intake in a Nepalese population with low blood pressure. J Hum Hypertens. 1993 Apr;7(2):131-40.[PMID]

7. World Health Organisation Guideline. Sodium intake for adults and children. Geneva: World Health Organisation2012.[Full Text]

8. Wright CA. Preliminary survey of attitudes to, and factors affecting perceived success or failure among adults attending a hospital lipid clinic. J Hum Nutr Diet. 1994;7(2):153-9.[DOI]

9. Welch JL, Bennett SJ, Delp RL, Agarwal R. Benefits of and barriers to dietary sodium adherence. West J Nurs Res. 2006 Mar;28(2):162-80; discussion 81-9.PMID; 16513918.[DOI]

10. Bentley B, De Jong MJ, Moser DK, Peden AR. Factors related to nonadherence to low sodium diet recommendations in heart failure patients. Eur J Cardiovasc Nurs. 2005 Dec;4(4):331-6.[PMID][DOI]

11. de Brito-Ashurst I, Perry L, Sanders TA, Thomas JE, Yaqoob MM, Dobbie H. Barriers and facilitators of dietary sodium restriction amongst Bangladeshi chronic kidney disease patients. J Hum Nutr Diet. 2011 Feb;24(1):86-95. [PMID] [DOI]

12. Kittle B. A Practical Guide to Conducting a Barrier 
Analysis. New York, NY: Helen Keller International. 2013. [Full Text]

13. Chung SJ, Kim D, Park MJ, KimYS, Kim JS, Jung HC, et al. Metabolic syndrome and visceral obesity as risk factors for reflux oesophagitis: a cross-sectional case-control study of 7078 Koreans undergoing health check-ups. Gut. 2008 Oct;57(10):1360-5.[PMID][DOI]

14. Rosenstock IM. The health belief model and preventive health behavior. Health Education \& Behavior. 1974;2(4):354-86.[Full Text]

15. Ajzen I, Driver B. Prediction of leisure participation from behavioral, normative, and control beliefs: An application of the theory of planned behavior. Leisure Sciences. 1991;13(3):185-204.[DOI]

16. Bandura A. Self-efficacy: toward a unifying theory of behavioral change. Psychol Rev. 1977;84(2):191.[PMID]

17. Janz N, Champion V, Strecher V. The health belief model. Glanz K, Rimer B, Lewis F, editors. San Francisco: John Wiley and Sons; 2002.

18. Firth D. Bias reduction of maximum likelihood estimates. Biometrika. 1993;80(1):27-38.[DOI]

19. Desharnais R, Bouillon J, Godin G. Self-efficacy and outcome expectations as determinants of exercise adherence. Psychol Rep. 1986.[Full Text]

20. Brady BA, Tucker CM, Alfino PA, Tarrant DG, Finlayson GC. An investigation of factors associated with fluid adherence among hemodialysis patients: a self-efficacy theory based approach. Ann Behav Med. 1997;19(4):33943.[PMID][DOI]

21. Gee ME, Bienek A, Campbell NRC, Bancej CM, Robitaille C, Kaczorowski J, et al. Prevalence of, and Barriers to, Preventive Lifestyle Behaviors in Hypertension (from a National Survey of Canadians With Hypertension). Am J Cardiol. 2012;109:570 - 5.[PMID][DOI]

22. DiMatteo MR. Social support and patient adherence to medical treatment: a meta-analysis. Health Psychol. 2004 Mar;23(2):207-18.[PMID][DOI]

23. Newson RS, Elmadfa I, Biro G, Cheng Y, Prakash V, Rust $\mathrm{P}$, et al. Barriers for progress in salt reduction in the general population. An international study. Appetite. 2013 Dec; 71:22-31.[PMID][DOI]

24. Saavedra-Garcia L, Bernabe-Ortiz A, Gilman RH, DiezCanseco F, Cardenas MK, Sacksteder KA, et al. Applying the Triangle Taste Test to Assess Differences between Low Sodium Salts and Common Salt: Evidence from Peru. PLoS One. 2015;10(7):e0134700.[PMID][DOI]
25. Mu J, Liu Z, Liu F, Xu X, Liang Y, Zhu D. Family-based randomized trial to detect effects on blood pressure of a salt substitute containing potassium and calcium in hypertensive adolescents. Am J Hypertens. 2009 Sep;22(9):943-7.[PMID][DOI]

26. World Health Organization. Salt as a Vehicle for Fortification, Report of a WHO Expert Consultation. 2008.[Full Text]

27. Acharya M, Acharya B, Sharma S. Women in Nepal: Country briefing paper. Asian Development Bank, Manila. 1999.[Full Text]

28. Acharya DR, Bell JS, Simkhada P, van Teijlingen ER, Regmi PR. Women's autonomy in household decision-making: a demographic study in Nepal. Reprod Health. 2010;7:15. [PMID]

29. Gallant MP, Spitze GD, Prohaska TR. Help or hindrance? How family and friends influence chronic illness selfmanagement among older adults. Research on Aging. 2007;29(5):375-409.[DOI]

30. World Health Organization. Reducing Salt Intake In Populations : Report of a WHO Forum and Technical meeting 5-7 October 2006, Paris, France. Geneva, Switzerland.2007.[Full Text]

31. Evangelista L, Doering LV, Dracup K, Westlake C, Hamilton M, Fonarow GC. Compliance behaviors of elderly patients with advanced heart failure. J Cardiovasc Nurs. 2003 Jul-Aug;18(3):197-206; quiz 7-8.[PMID]

32. Hawkshead J, Krousel-Wood MA. Techniques for measuring medication adherence in hypertensive patients in outpatient settings. Disease Management \& Health Outcomes. 2007;15(2):109-18.[DOI]

33. Ford CD, Kim MJ, Dancy BL. Perceptions of hypertension and contributing personal and environmental factors among rural Southern African American women. Ethn Dis. 2009 Autumn;19(4):407-13.[PMID] 